\title{
SPATIAL DISTRIBUTION OF DOMINANT PLANTS SPECIES ACCORDING TO LOCAL ENVIRONMENTAL GRADIENTS
}

\author{
DYAKOV, N. R. \\ Dendrology Department, University of Forestry \\ 10 Kliment Ohridski Blvd. 1797, Sofia, Bulgaria \\ e-mail:nickydyakov@gmail.com
}

(Received $20^{\text {th }}$ Sep 2015; accepted $8^{\text {th }}$ Jan 2016)

\begin{abstract}
At the current stage of vegetation ecology development as a science it has not been reached consensus between the competing theories trying to explain vegetation pattern emerging under the influence of underlying environmental gradients. It is still not clear what is the response of different plant species towards the influence of complex gradients? This study tries to revise some classical and temporary hypotheses concerning species response surface/curve shape along environmental gradients whether it is symmetric (Gaussian) or with other shape. It also attempts to check if species modes along complex gradients are distributed randomly, uniformly or they are clumped, as well as to inspect the species mode distribution among species importance value octaves - whether it is lognormal or lograndom. Field samples were gathered using gradsect method for laying down sampling plots. Obtained data were analyzed in the context of four complex gradients - elevation, habitat dryness, slope inclination and slope convexity. CCA ordination, GAM and LOEES regression and nonparametric correlation were used as analyzing tools. We have found that species response surface/curves do not have symmetric shape but rather they show asymmetric and complex forms. Mode distribution of dominant tree and shrub species was random but that of herbs followed clumped pattern. When species mode distribution was divided into octaves, trees and shrubs showed lograndom distribution but all species together had lognormal one. Herbs alone do not conform to neither lognormal nor lograndom distributional patter. It seems that each species has its own response shape towards the environment, determined by its physiology, interaction with other species and historical events. It is hoped that the current study will add a little drop to the vast ocean of vegetation ecology knowledge helping with the clarification of the basic understanding of the vegetation pattern.
\end{abstract}

Keywords: elevation, habitat dryness, distribution fitting, response surfaces/curves

\section{Introduction}

At the current stage of vegetation ecology development as a science it has not been reached consensus between the competing theories trying to explain vegetation pattern emerging under the influence of underlying environmental gradients (Austin, 2005). There have been different concepts, starting with the F. Clements's "super organismic" hypothesis (Clements, 1936) standing on the one end of the spectrum and reaching the other end with the "individualistic paradigm" of H. A. Gleeson (Gleason, 1926). Another popular theory is based on the concept of the ecological niche and the equal partitioning of resource gradients between the plant species (Ter Braak and Prentice, 1988). According to a third paradigm, each plant layer shares the environmental resources independently, and also, resource sharing between the dominant and rare plant species is independent (Gauch and Whittaker, 1972). Still another hypothesis holds that the reaction of plant species to the environmental gradients changes according to their position along the corresponding gradient (Austin, 1999).

Using a simulation of species population distribution along the environmental gradients, Gauch and Whittaker (1972) raised several hypothesis trying to clarify plant species response to the complex environmental gradients: 1) species "importances" 
along the cenocline forms approximately normal (Gaussian) curves; 2) "minor" species modes are distributed along the complex gradients randomly, but the modes of dominant species are dispersed uniformly, so that the competition between them to be minimized; 3) when the modes of the tree species are grouped along the environmental gradients in octaves (classes), then the number of species in the classes is approximately equal, implying lograndom distribution; 4) when modes of forest herbs and shrubs are grouped by octaves, the number of species in octaves is uneven, suggesting lognormal distribution. Later, other authors (Austin, 1980; Austin, 1985; Austin, 1987; Austin, 2002; Austin 2005; Austin et al., 1984; Austin and Smith, 1989; Guisan et al., 1999; Minchin, 1989; Peet and Loucks, 1977) also tried to bring light on the topic with variable success.

Recently, predictive modelling of species distribution has become a powerful tool in tackling different problems in the vegetation ecology, biogeography, evolutionary biology, as well as in the conservation biology and global climate change studies (Guisan and Thuiller, 2005). Species spatial distribution models are empirical models, connecting field observations with the predictive environmental variables, based on statistically or theoretically obtained species response surfaces (Guisan and Zimmermann, 2000). Species data can be qualitative, i.e. presence/absence, or quantitative, resulting from random or stratified field sampling (Guisan and Thuiller, 2005).

It is well known that the dominant species in a given vegetation express it structure and composition best, therefore they became principal object of the vegetation-environment relationship analyses. Dominant plants determine, to a greater extent, the conditions for the existence of other plant species. They also characterize the different vegetation types and indicate the habitat conditions in the places where are found. Because of this they can be the key for understanding vegetation pattern (Whittaker, 1956).

Using contemporary methods for ordination, correlation and regression analyses of plant species distribution this study attempts to test some of the classic and modern hypotheses, concerning vegetation structure and composition. We go further and test species mode distribution along environmental gradients for negative binomial distribution, implying that plant species have clumped patterns (Krebs, 1999). For the successful application of the referred methods it is obligatory that the analyzed plant species can be found in greatest number of samples. This is the reason why in the current study we have used only the dominant plant species found in the studied area.

It is worth mentioning also that the current research is not based on a priori assumption for the existence of presumed plant associations but on the analysis of the obtained samples in the context of underlying environmental gradients. We adhere to the understanding that the adequacy of vegetation description is founded upon the studying of species population, dispersed along the environmental gradients, which offers the opportunity to test the already mentioned hypotheses.

\section{Material and methods}

\section{Study area}

The study site, called Vitosha Mountain, is located in Western Bulgaria. It is characterized with compactness and well expressed elevation gradient. The mountain has steep slopes and variable expositions. Its vegetation has variable species composition. The current study embraced the south slope of the mountain. GPS

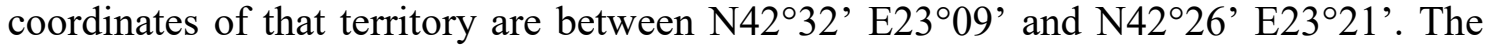


area covers $118 \mathrm{~km}^{2}$. For details about the studied area refer to Dyakov (2012), Dyakov (2013), Dyakov (2014).

\section{Sampling}

Sampling strategy was based on gradsect method of Austin and Heyligers (1990). Its advantages are: 1) relatively cheap, 2) highly effective, 3) easy to apply on the field but requiring experienced workers. During the summers of 2008 and 2009, generally 159 (0.1 ha) samples were taken. The gradsect method's design ensures that the gathered samples encompass the greatest variety of environmental condition (elevations, slopes, aspects, topographies) throughout the studied territory, covering greatest portion of the realized niche space of most plant species in the area. Species Importance Value (Curtis, 1959), used in all analyses, was calculated as mean value of species' density, cover and frequency. It is popular measure of species significance in the sampled vegetation (van der Maarel and Franklin, 2012) because it combines important aspects of species' quantitative occurrence. Detailed information on the field techniques can be found in previous papers (Dyakov, 2012; Dyakov, 2013; Dyakov, 2014; Dyakov and Zhelev, 2013).

\section{Quantifying the environmental gradients}

Four indirect or factor-complex (Whittaker, 1978) environmental gradients were used elevation, habitat dryness, slope inclination and slope convexity. According to Austin and Smith (1989) and Austin (2005), indirect gradients influence direct gradients, such as temperature and rainfall, which in turn have direct effect on plant growth. On a local scale, however, the authors recommend measuring and using indirect gradients because they have much more meaningful influence on vegetation pattern and processes. Elevation and slope inclination variables were input to the analyses with their direct measurements in meters above sea level and degrees, respectively. Habitat dryness and slope topography were quantified using the methodology of Whittaker (1956). For complete procedure on gradient quantification methodology refer to Dyakov (2012).

\section{Outlining the coarsest pattern of vegetation}

The general picture of the vegetation pattern in the environmental space was outlined with direct gradient analysis using Canonical Correspondence Analysis (CCA) (ter Braak, 1986). Being a method for direct gradient analysis CCA explains the variation in the data on the basis of preliminary chosen environmental gradients (Jongman et al., 1995). The main advantages of CCA are: 1) the simultaneous ordering of sites and species (if needed), 2) rapid computation, 3) very good performance when species have nonlinear and unimodal relationships to environmental gradients, and 4) robustness to violation of preliminary assumptions (Palmer, 1993).

\section{Describing the detailed relationship between plant species and environmental gradients}

Trying to reveal the detailed relationships between the species distribution and the environmental gradients, we used nonparametric regression and correlation techniques. Because correlated variables were not normally distributed we used nonparametric correlation coefficient of Spearman, Rs (Spearman, 1904). 
The aim of regression analysis is to describe the dependent variable as a function of one or multiple independent ones. Using regression analyses, dependent variables can be predicted (described) with minimal or less statistical error (Jongman et al., 1995). General Additive Models (GAM) were used as a nonlinear regression method. The aim of GAM models is to maximize the quality of the dependent variable description which may have various distributions. GAM does so by developing unspecified nonparametric functions of the independent variables which are "connected" with the depended variable by link function. Numerous advantages are making GAM usage in current ecological studies an indispensable tool (Franklin, 1998; Thuiller et al., 2003; Yee and Mitchell, 1991).

As a better method for visual representation of response surfaces, Locally Weighted Regression (LOESS) (Cleveland and Devlin, 1988) was used. It is one of the contemporary modelling techniques intending to overcome some of the drawbacks of the classical ones. LOESS combines the simplicity of the least square methods together with the flexibly of nonlinear regression. This is a procedure for building of regression surfaces by multivariate smoothing. Dependent variable is smoothed in a moving fashion as a function of the independent variables analogous to a moving average time series computation (Cleveland and Devlin, 1988).

The most parsimonious regression model was selected with the aim of Akaike Information Criterion (AIC). AIC checks the models for goodness-of-fit and parsimony and rejects the very complex ones (Carol et al., 2006). According to Thuiller et al. (2003) AIC allows the removal of variable redundancy and multicollinearity problems too.

\section{Testing hypotheses}

CCA ordination axes were tested for significance with Monte Carlo Permutation test (Jongman et al., 1995).

The ecological response surfaces of dominant plant species were classified as symmetric, asymmetric and complex (having more than one mode) (Minchin, 1989). The hypothesis that the ecological response surface distribution does not differ between the growth forms (trees, shrubs and herbs) was tested with ANOVA, Holm- Śídák method (Holm, 1979).

Using the methodology of Minchin (1989), mode frequency distribution was examined by calculation of the number of species reaching their maximal mean importance value in the ecological space defined by the elevation and habitat dryness. If the modes are randomly distributed then they should have Poisson distribution. This hypothesis was tested with Chi-squared goodness-of-fit test (Krebs, 1999; Zar, 2010) for the modes of all species and by growth forms. Then, using Kolmogorov-Smirnov goodness-of-fit test (Zar, 2010), variables for which Poisson distribution hypothesis was rejected, were tested for Negative Binomial distribution, implying clumped pattern. Moreover, we analyzed mode distribution of the "mass" species (Minchin, 1989) or the 25 plant species with maximal importance value. For the species with complex ecological surface, the mode with the greatest value was used.

Mode frequency distribution for all dominant plant species and by growth forms was also tested for lognormal and lograndom distribution using again Kolmogorov-Smirnov goodness-of-fit test. In all statistical tests the significance level was $\mathrm{P}<0.05$ unless shown otherwise. 
In all analyses the following specialized software products were used: SigmaPlot for Windows, version 12.3 (Systat Software, 2011); CANOCO for Windows, version 4.51 (ter Braak and Šmilauer, 1997-2003); CanoDraw for Windows, version 4.1 (Šmilauer, 1999-2003).

\section{Results}

\section{General picture of plant species/environmental gradient relationship}

Generalized picture of the dominant plant species positioning in the abstract ecological space is shown on Figure 1.

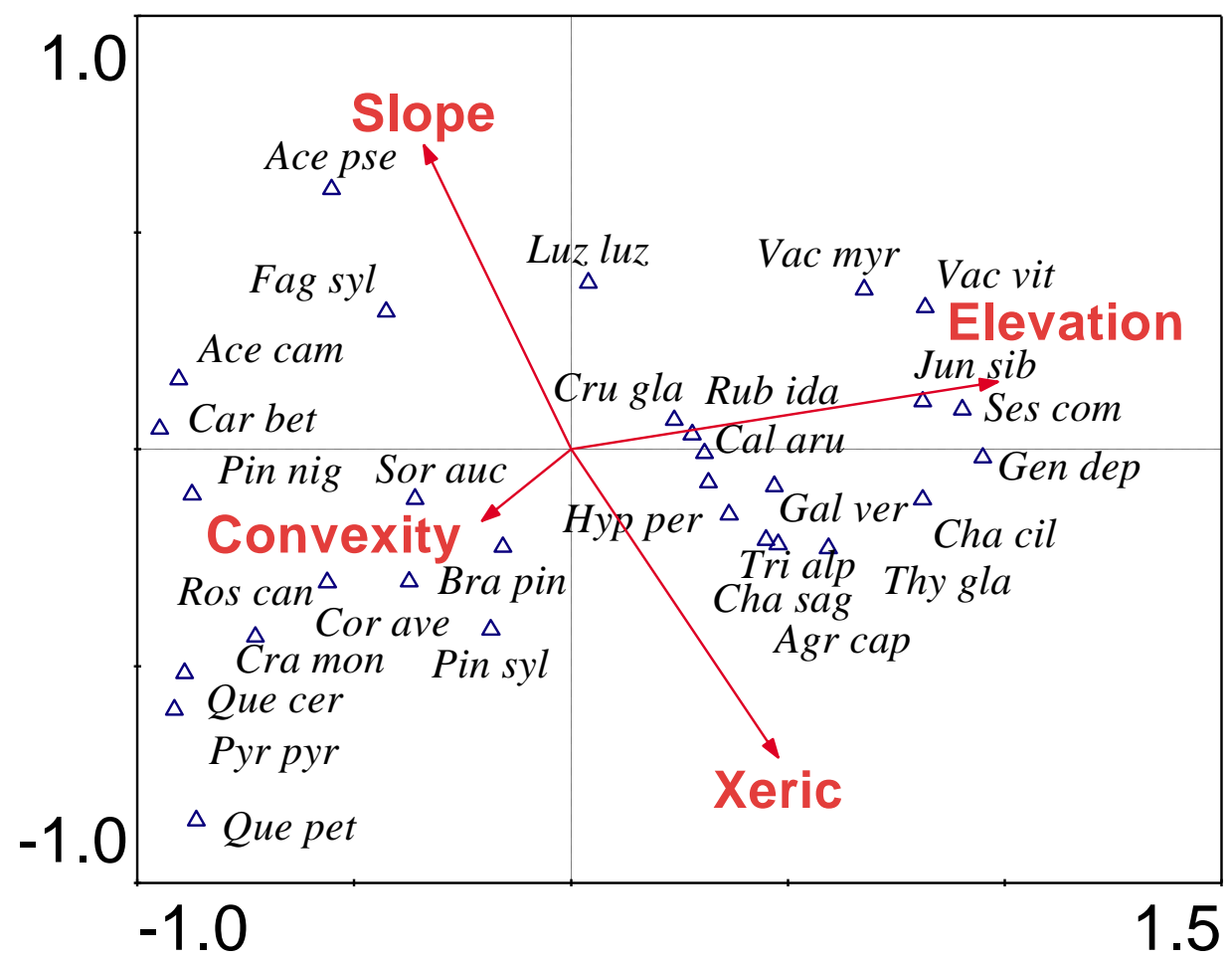

Figure 1. CCA ordination of the 30 dominant plant species (trees, shrubs and herbs) along with the local indirect environmental gradients. Elevation = altitude $(\mathrm{m}) ;$ Xeric = habitat dryness; Slope $=$ slope inclination $\left({ }^{\circ}\right)$; Convexity $=$ slope convexity. Plant species are designated with the first three letters of their genus and species names as follows: Ace cam = Acer campestre L.; Ace pse = Acer pseudoplatanus L.; Agr cap = Agrostis capillaris L.; Bra pin = Brachypodium pinnatum (L.) P.Beauv.; Cal aru = Calamagrostis arundinacea (L.) Roth; Car bet $=$ Carpinus betulus L.; Cha cil = Chamaecytisus ciliatus (Wahlenb.) Rothm.; Cha sag = Chamaespartium sagittale (L.) P.E.Gibbs; Cor ave = Corylus avellana L.; Cra mon = Crataegus monogyna Jacq.; Cru gla = Cruciata glabra (L.) Ehrend.; Fag syl = Fagus sylvatica L.; Gal ver = Galium verum L.; Gen dep = Genista depressa M. Bieb.; Hyp per $=$ Hypericum perforatum L.; Jun sib = Juniperus sibirica Burgsd.; Luz luz = Luzula luzuloides (Lam.) Dandy; Pin nig = Pinus nigra J.F.Arnold; Pin syl = Pinus sylvestris L.; Pyr pyr = Pyrus pyraster (L.) Burgsd.; Que cer $=$ Quercus cerris L.; Que pet $=$ Quercus petraea (Matt.) Liebl.; Ros can = Rosa canina L.; Rub ida = Rubus idaeus L.; Ses com = Sesleria comosa Velen.; Sor auc = Sorbus aucuparia L.; Thy gla = Thymus glabrescens Willd.; Tri alp = Trifolium alpestre L.; Vac myr = Vaccinium myrtillus L.; Vac vit = Vaccinium vitis-idaea $\mathrm{L}$. 
Trying to save space and to be clearer, only the 30 most abundant plant species in the studied area - found in all 159 sampling plots - were plotted. Environmental gradients are depicted with arrows. The statistical test of the CCA axes is confirmed at $P=0.002$ level. We interpret the first two CCA axes as expressions of the elevation gradient (first, horizontal axis, variance explained $=16.2 \%$ ) and the habitat dryness gradient (second, vertical axis, variance explained $=4.9 \%)($ Fig. 1$)$. Our interpretation is inferred by the acute angles between the two CCA axes and the arrows of the corresponding environmental gradients. Furthermore, at the two right quadrants of the figure are located plant species occurring mainly at higher elevation habitats, while at the two left ones are positioned species dominating at lower altitude. On the other hand, in the upper parts of the figure are located plant species preferring moister habitats, while the lower parts are occupied by species found in more xeric places. Possible explanation of the opposite direction of the slope inclination and habitat dryness gradient arrows is that moistest habitats tend to occur on the slopes' lower parts where the slope inclination tends to be highest. On the other hand, most xeric habitats are mainly located on the upper parts of the slopes (summits) where the inclination tends to be lowest. It seems that slope inclination and habitat dryness are weakly dependent on the elevation per se but are influenced more strongly by their actual topographic position across the mountainous territory.

From Figure 1 it can be witnessed that the different plant species are dispersed in the four quadrants according to their habitat requirements where the four environmental gradients have prevailing influence. Because most correlations between slope convexity and plant species distribution happened to be not significant (Table 1), for now we will concern ourselves mainly with the interpretation of the first three environmental gradients. In the left upper part of Figure 1 are localized species like Acer pseudoplatanus, Fagus sylvatica and Acer campestre. They dominate in relatively moist habitats on steep slopes at middle to low elevation. In the low left quadrant are centered species like Quercus petraea, Pyrus pyraster, Quercus cerris, Crataegus monogyna, Pinus sylvestris, Brachypodium pinnatum and Rosa canina. These species are distributed mainly in more or less xeric habitats at low and middle elevation. On the other hand, species like Carpinus betulus, Sorbus aucuparia and Pinus nigra are localized in the central part of the graph implying that they do not strictly prefer any specific set of environmental conditions and can be found to dominate in variable places at low and middle altitude. The right quadrant is occupied by species dominating at higher elevations. In the upper right part are positioned species like Vaccinium myrtillus, Vaccinium vitis-idaea, Juniperus sibirica and Sesleria comosa occupying more mesic habitats at highest elevation. In the lower right part are localized species like Chamaecytisus ciliatus, Thymus glabrescens, Agrostis capillaris, Chamaespartium sagittale, Trifolium alpestre and Galium verum which dominate in more xeric habitats at greater elevation. Other species, like Cruciata glabra, Luzula luzuloides, Calamagrostis arundinacea, Hypericum perforatum and Rubus idaeus, as already mentioned, tend to occupy the central parts which indicates that they are adapted to wider spectrum of environmental conditions.

\section{Detailed relationships between plant species and environmental gradients}

Spearman correlations between the species importance value and local environmental gradients are summarized in Table 1 . 
Table 1. Spearman (Rs) correlations between the dominant plant species' importance value and local environmental gradients in the studied area. Correlation coefficients greater than \pm 0.4 are marked with Bold.

$* P<0.05 ; * * P<0.01 ; * * * P<0.001 ; n s=$ not significant

Local (complex) environmental gradients

\begin{tabular}{lll} 
Dominant plant species & Elevation $(\mathrm{m})$ Habitat dryness Slope inclination $\left({ }^{\circ}\right)$ & Slope convexity \\
\hline
\end{tabular} Trees

\begin{tabular}{|c|c|c|c|c|}
\hline Acer campestre & $-0.430 * * *$ & $-0.178 *$ & $n s$ & $n s$ \\
\hline Acer pseudoplatanus & $n s$ & $-0.250 * *$ & $n s$ & $-0.182 *$ \\
\hline Carpinus betulus & $-0.551 * * *$ & $-0.172 *$ & $n s$ & $n s$ \\
\hline Fagus sylvatica & $-0.433 * * *$ & $-0.423 * * *$ & $0.459 * * *$ & $0.198 *$ \\
\hline Pinus nigra & $-0.347 * * *$ & $-0.188 *$ & $-0.166^{*}$ & $n s$ \\
\hline Pinus sylvestris & $n s$ & $0.229 * *$ & $-0.360 * * *$ & $-0.179 *$ \\
\hline Pyrus pyraster & $-0.351 * * *$ & $n s$ & $n s$ & $n s$ \\
\hline Quercus cerris & $-0.584 * * *$ & $n s$ & $n s$ & $n s$ \\
\hline Quercus petraea & $-0.372 * * *$ & $n s$ & $n s$ & $n s$ \\
\hline Sorbus aисираria & $n s$ & $-0.204 *$ & $n s$ & $n s$ \\
\hline \multicolumn{5}{|l|}{ Shrubs } \\
\hline Chamaecytisus ciliatus & $0.495 * * *$ & $0.364 * * *$ & $-0.266 * *$ & $n s$ \\
\hline Chamaespartium sagittale & $0.456 * * *$ & $0.410 * * *$ & $-0.358 * * *$ & $n s$ \\
\hline Corylus avellana & $-0.492 * * *$ & $n s$ & $n s$ & $n s$ \\
\hline Genista depressa & $0.493 * * *$ & $0.286^{* * *}$ & $-0.305 * * *$ & $n s$ \\
\hline Juniperus communis & $n s$ & $0.238 * *$ & $n s$ & $n s$ \\
\hline Juniperus sibirica & $0.756 * * *$ & $0.351 * * *$ & $-0.381 * *$ & $-0.173 *$ \\
\hline Rosa canina & $-0.281 * * *$ & $n s$ & $-0.233 * *$ & $n s$ \\
\hline Rubus idaeus & $0.435 * * *$ & $n s$ & $-0.160 *$ & $-0.276 * * *$ \\
\hline Vaccinium myrtillus & $0.644 * * *$ & $n s$ & $-0.201 *$ & $-0.251 * *$ \\
\hline Vaccinium vitis-idaea & $0.547 * * *$ & $n s$ & $-0.204 *$ & $-0.192 *$ \\
\hline \multicolumn{5}{|l|}{ Herbs } \\
\hline Agrostis capillaris & $0.389 * * *$ & $0.358 * * *$ & $-0.443 * * *$ & $n s$ \\
\hline Brachypodium pinnatum & $n s$ & $0.281 * * *$ & $n s$ & $n s$ \\
\hline Calamagrostis arundinacea & $0.460 * * *$ & $0.346 * * *$ & $-0.256 * *$ & $n s$ \\
\hline Cruciata glabra & $0.393 * * *$ & $0.212 * *$ & $-0.258 * *$ & $n s$ \\
\hline Galium verum & $0.574 * * *$ & $0.313 * * *$ & $-0.399 * * *$ & $n s$ \\
\hline Hypericum perforatum & $0.334 * * *$ & $0.308 * * *$ & $-0.381 * * *$ & $n s$ \\
\hline Luzula luzuloides & $0.319 * * *$ & $-0.162 *$ & $n s$ & $n s$ \\
\hline Sesleria comosa & $0.707 * * *$ & $0.315 * * *$ & $-0.372 * * *$ & $n s$ \\
\hline Thymus glabrescens & $0.598 * * *$ & $0.437 * * *$ & $-0.361 * * *$ & $n s$ \\
\hline Trifolium alpestre & $0.300 * * *$ & $0.287 * * *$ & $-0.451 * * *$ & $n s$ \\
\hline
\end{tabular}

Most trees are negatively correlated with the elevation but most strongly are Quercus cerris and Carpinus betulus. The same applies to the relationship with the habitat dryness but most mesophyllic are Fagus sylvatica and Acer pseudoplatanus. The European beech correlates most strongly positively with the slope gradient contrary to Pinus sylvestris which dominates on gentle slopes. Obviously, slope convexity is of less importance for the plant species because most of them show weak relationship, which could be explained with the very continuous, gentle change 
of this variable across the landscapes compared to slope inclination, habitat dryness and elevation.

Most shrubs correlate strongly with the elevation (Table 1). Positive relationship show Chamaecytisus ciliatus, Chamaespartium sagittale, Juniperus sibirica, Vaccinium myrtillus and Vaccinium vitis-idaea but highly negatively correlated are species like Corylus avellana and Rosa canina. Some species, like Chamaespartium sagittale, Juniperus sibirica and Chamaecytisus ciliatus, correlate highly positively with the xeric habitats, and slightly more weakly, species like Genista depressa and Juniperus communis. Most shrub species correlate negatively with slope inclination but most strongly do species like Chamaespartium sagittale and Juniperus sibirica.

Almost all herbs show clear tendency in relation to the elevation (Table 1). Most of them are highly positively correlated with it. These are species like Sesleria comosa, Thymus glabrescens, Calamagrostis arundinacea and Galium verum. Most herbs are positively correlated with the xeric habitats but most strongly correlate species like Thymus glabrescens, Galium verum, Hypericum perforatum and Agrostis capillaris. There is one species that shows the opposite trend - Luzula luzuloides. Almost all herbs are significantly negatively correlated with slope inclination.

\section{Plant response surfaces in the context of the local environmental gradients}

Detailed analysis of the dominant plant species spatial distribution was done with nonlinear regression where the independent variables were the complex environmental gradients and dependent variable was the species importance value in the sample. Figure 2 shows species response surfaces of the dominant tree species in the context of the four main environmental gradients - elevation, habitat dryness, slope inclination and slope convexity. Isolines show the species importance value.
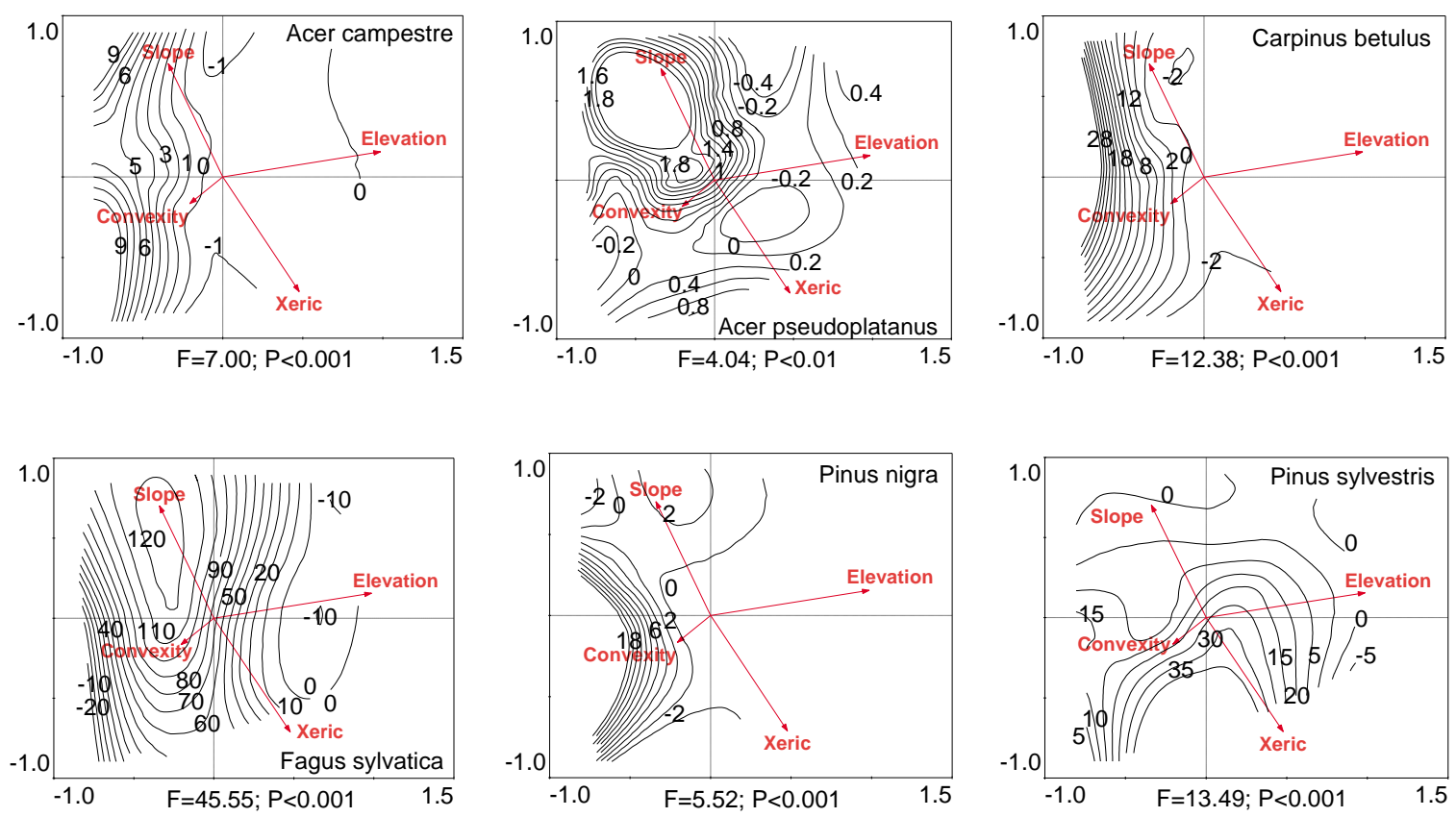

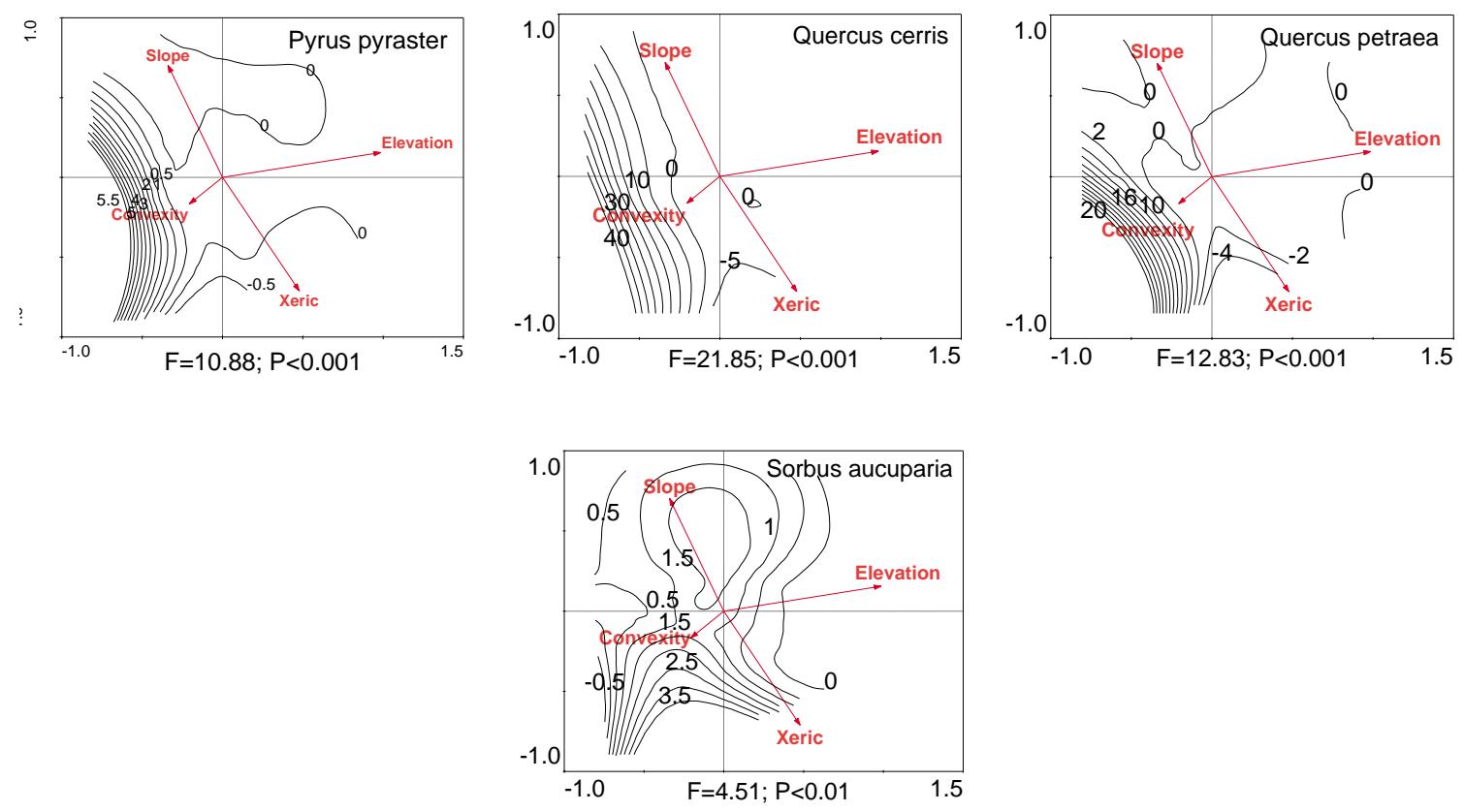

Figure 2. GAM response surfaces of 10 dominant tree species along with the local environmental gradients. Isolines show the importance value of the plant species. Each response surface was tested for significance and the result is shown in the lower part of the subgraphs.

From Figure 2 it can be witnessed that most trees have restricted distribution to a particular set of conditions or parts of the local environmental gradients. For example, species like Pinus nigra, Carpinus betulus, Pyrus pyraster, Acer campestre, Quercus petraea, Q. cerris and Acer pseudoplatanus are found at lower elevation mainly in mesic and submesic habitats. On the other hand, species like Fagus sylvatica, Pinus sylvestris and Sorbus aucuparia occupy broader spectrum of environments and can be found from the most mesic to the most xeric habitats across the whole studied area.

Dominant shrub distribution is shown on Figure 3.

Shrub species can be grouped in several groups. The first one includes species dominating at higher elevation in the xeric habitats, such as Chamaespartium sagittale and Chamaecytisus ciliatus. They have their maximum importance centered in the xeric subalpine habitats above $1500 \mathrm{~m}$. The second species shows secondary peak which is located at lower elevation in the open mesic habitats.

The second group of species dominate at higher elevation too, but they are distributed along the whole length of the dryness gradient. These are Genista depressa and Juniperus sibirica. They reach their maxima above $1700 \mathrm{~m}$ and Genista depressa is slightly more abundant in the subxeric habitats.

A third group includes two ericoid shrub species, Vaccinium myrtillus and Vaccinium vitis-idaea, which have almost analogous distribution. Their maxima are centered above $1700-1800 \mathrm{~m}$ in the submesic and mesic places. Their downward altitudinal limit appears at $1200 \mathrm{~m}$ elevation but, exceptionally, Vaccinium myrtillus can also be found in the most mesic habitats below this limit. It is also the more abundant species in the subalpine meadows. 

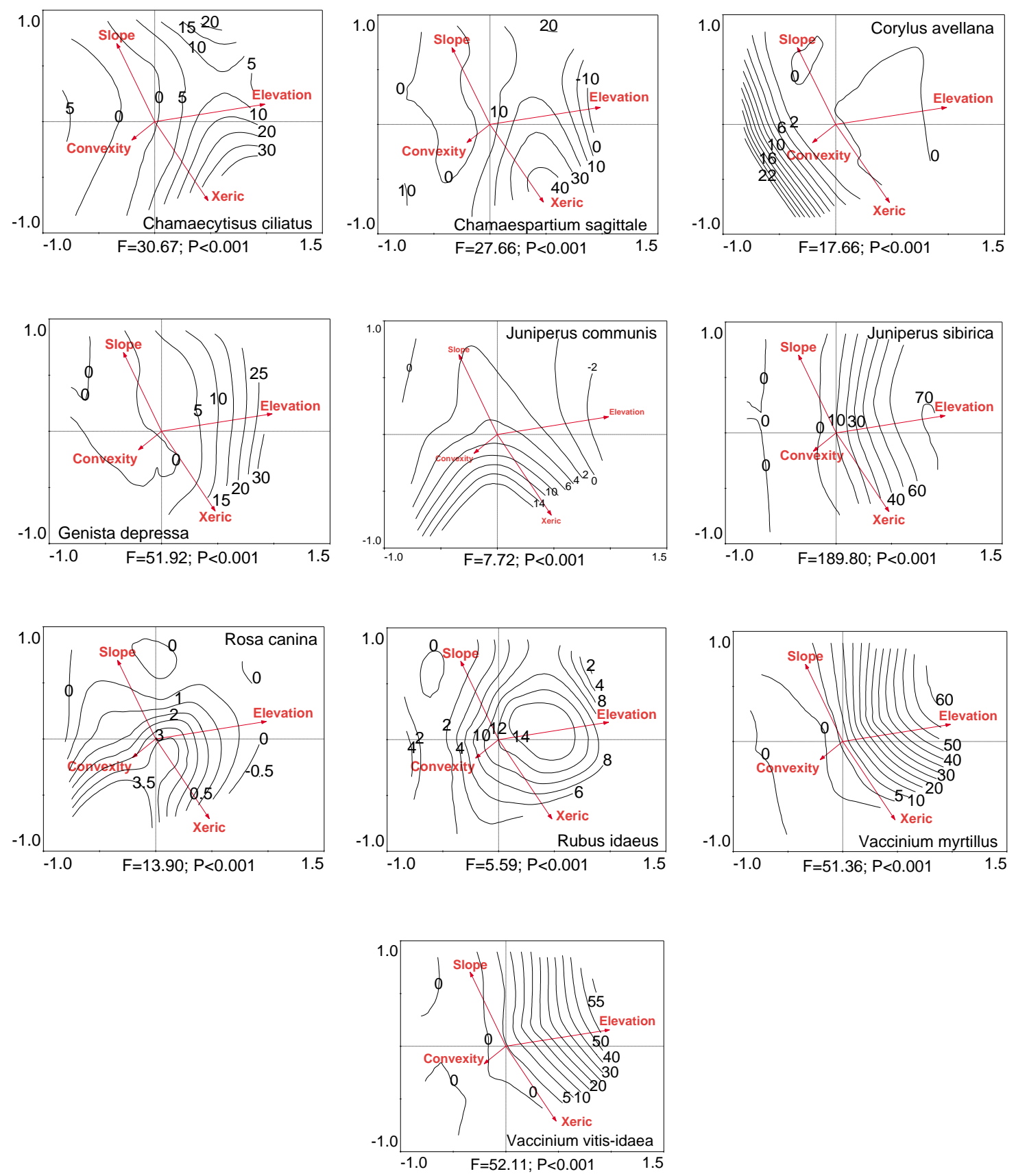

Figure 3. GAM response surfaces of 10 dominant shrub species along with the local environmental gradients. Isolines show the importance value of the plant species. Each response surface was tested for significance and the result is shown in the lower part of the subgraphs.

Another group includes species dominating at low elevation in the most xeric habitats, such as Corylus avellana and Rosa canina. Corylus avellana do not ascend above $1200 \mathrm{~m}$ or can be found above this elevation only in the most xeric conditions. The second species is found at greater elevation too (at about 1600-1700 m), but it is localized only in the more mesic end of the dryness gradient. 
Rubus idaeus has a peculiar distribution. It dominates in the submesic and subxeric habitats at about $1500 \mathrm{~m}$. Away from this distributional center its importance slowly decreases. Above 1800-1900 $\mathrm{m}$ it can rarely be found or is totally missing.

Spatial distribution of the dominant herb species in the studied territory is shown on Figure 4.
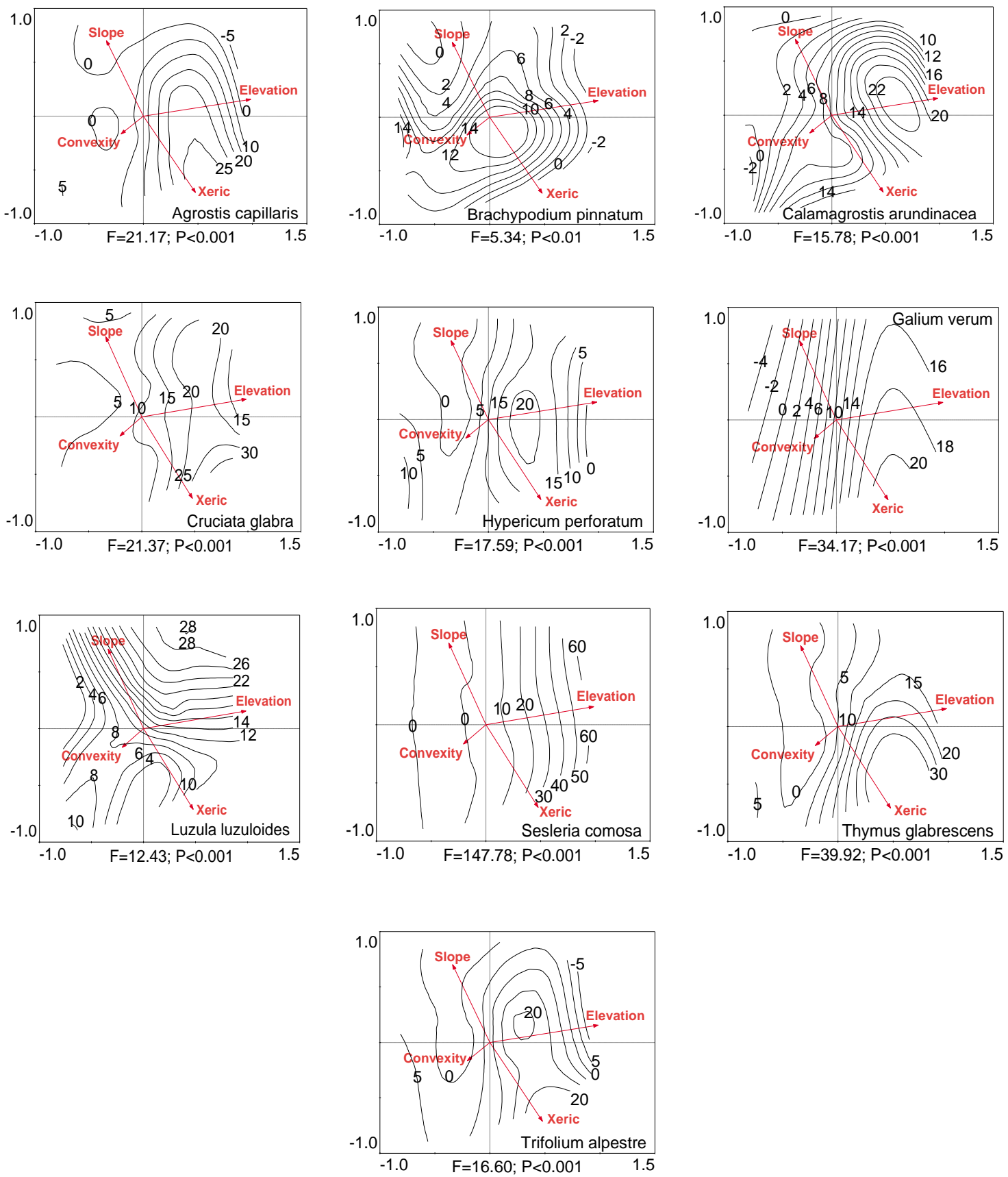

Figure 4. GAM response surfaces of 10 dominant herb species along with the local environmental gradients. Isolines show the importance value of the plant species. Each response surface was tested for significance and the result is shown in the lower part of the subgraphs. 
Similarly to the shrubs, herb species can be grouped into several groups with resembling distribution. In the first group fall species distributed in the xeric habitats at middle to higher elevation. These are Agrostis capillaris, Thymus glabrescens and Galium verum. The three species have maximum importance located in the xeric subalpine habitats (at about 1600-1700 m). With the decreasing elevation their dominance slowly diminishes reaching almost zero in the beech zone (1200-1400 m). However, they can again be found below $1100 \mathrm{~m}$ but in the xeric part of dryness gradient and with much lower importance.

Next group includes two species which dominate at higher elevation. These are Sesleria comosa and Calamagrostis arundinacea. The first species reaches its maximum at about 1900-2000 m having no specific environmental requirements or slightly displaced toward the mesic part of dryness gradient. With the elevation decrease, Sesleria comosa slowly loses its importance and below $1200 \mathrm{~m}$ it is completely missing. The second herb is centered at about $1700 \mathrm{~m}$ in the submesic places. Second, weaker, optimum appears at about $1400 \mathrm{~m}$ in the most xeric habitats. It can be found in the beech zone too, but with much less importance.

Another group unifies species with complex distribution like Brachypodium pinnatum, Luzula luzuloides and Cruciata glabra.

The next species with specific distribution is Hypericum perforatum. It reaches its maximum in the middle parts of dryness gradient at about 1550-1600 m. With the elevation increase Hypericum perforatum slowly disappears and above $1900 \mathrm{~m}$ it cannot be found. This species shows second weaker peak located at lower elevation in the open xeric meadows and woodlands, distributed on leveled or convex slopes. It is almost missing in the beech dominated zone.

Trifolium alpestre shows similar distributional pattern. It dominates at about $1600 \mathrm{~m}$ in the xeric habitats. Moving away towards the xeric places, its distributional zone widens. Moreover, with the elevation increase Trifolium alpestre loses importance, more quickly in the moister habitats. This species can also be found at much lower elevation, about and less than $1000 \mathrm{~m}$, in the most xeric places but with negligible importance. Similarly to the former herb species, most obviously in the mesic part of dryness gradient, the approaching of the beech zone causes its rareness and complete disappearance.

\section{Response surface shape}

Table 2 shows the response surface classification for all 100 analyzed species and grouped by growth form into trees, shrubs and herbs. Figure 5 and Figure 6 show species response curves along the two main complex gradients separately - elevation and habitat dryness. It can be witnessed that, with some minor exceptions, almost none of the dominant plant species shows symmetric response curve.

Table 2. Response surface shape of the 100 dominant plant species

\begin{tabular}{llll}
\hline & \multicolumn{3}{c}{ Response surface distribution } \\
\cline { 2 - 4 } Growth form & Symmetric & Asymmetric & Complex \\
\hline Trees & 1 & 8 & 2 \\
Shrubs & 1 & 10 & 5 \\
Herbs & 2 & 58 & 13 \\
\hline All species & 4 & 76 & 20 \\
\hline
\end{tabular}


The statistical test of species response surfaces of Table 2 shows that there are no statistical difference between the growth form groups $(\mathrm{F}=1.297 ; \mathrm{df}=2 ; \mathrm{P}=0.340)$. Moreover, most response surfaces $(76 \%)$ had asymmetric form, $20 \%$ were with bimodal or complex distribution, and only $4 \%$ of the species had symmetric surface (Table 2).
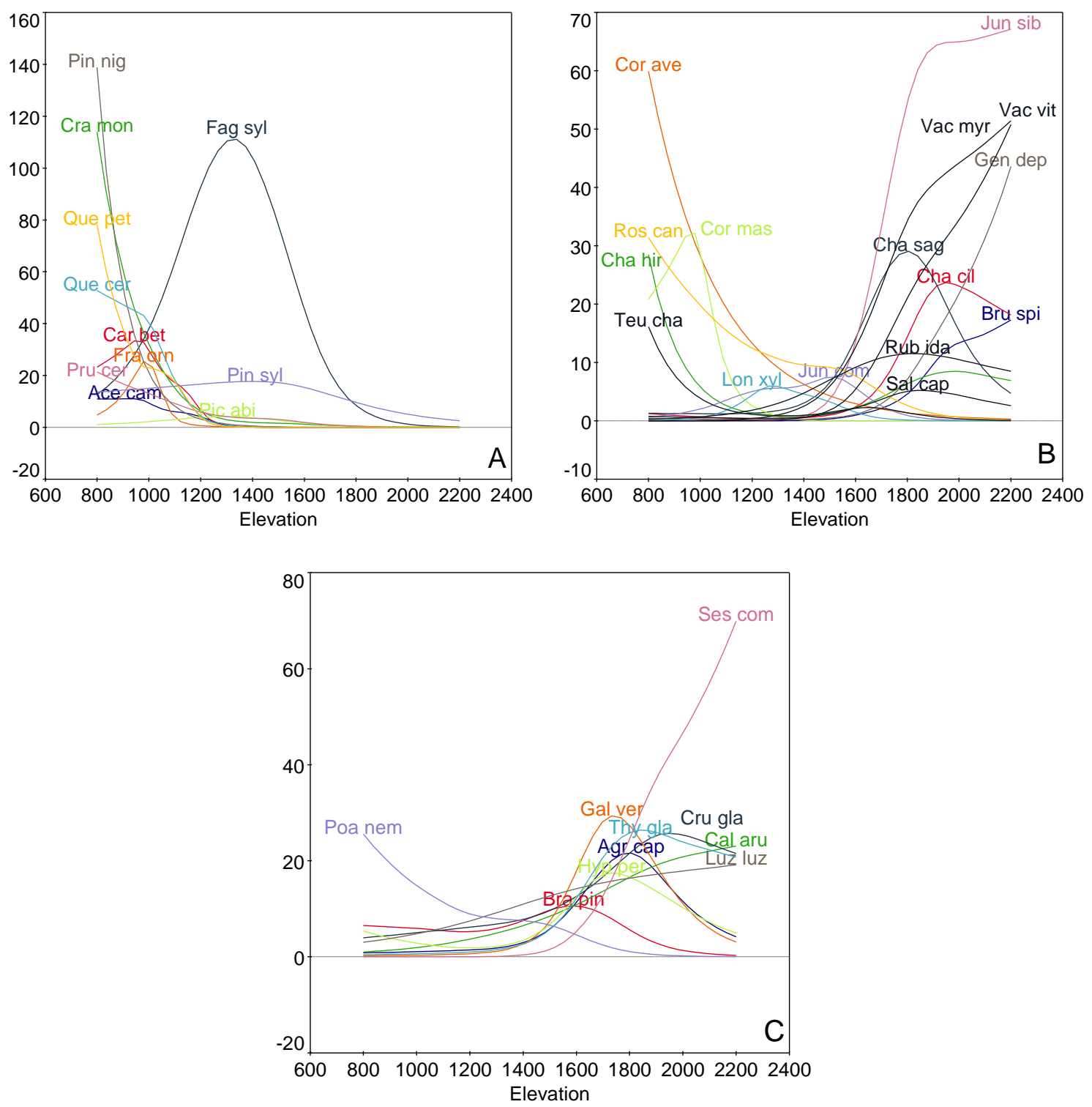

Figure 5. Response curves of dominant plant species along elevation gradient. $a=$ Trees; $b=$ Shrubs; $c=$ Herbs. Species names are coded with the first three letters of the genus and species names (see Fig. 1). Species names not shown in Fig. 1 are as follows: Bru spi = Bruckenthalia spiculifolia (Salisb.) Rchb.; Cha hir = Chamaecytisus hirsutus Link; Fra orn = Fraxinus ornus L.; Jun com = Juniperus communis L.; Lon xyl = Lonicera xylosteum L.; Pic abi $=$ Picea abies (L.) H.Karst.; Pru cer = Prunus cerasifera Ehrh.; Sal cap = Salix capraea L.; Poa nem = Poa nemoralis $L$.; Teu cha = Teucrium chamaedrys $L$. 

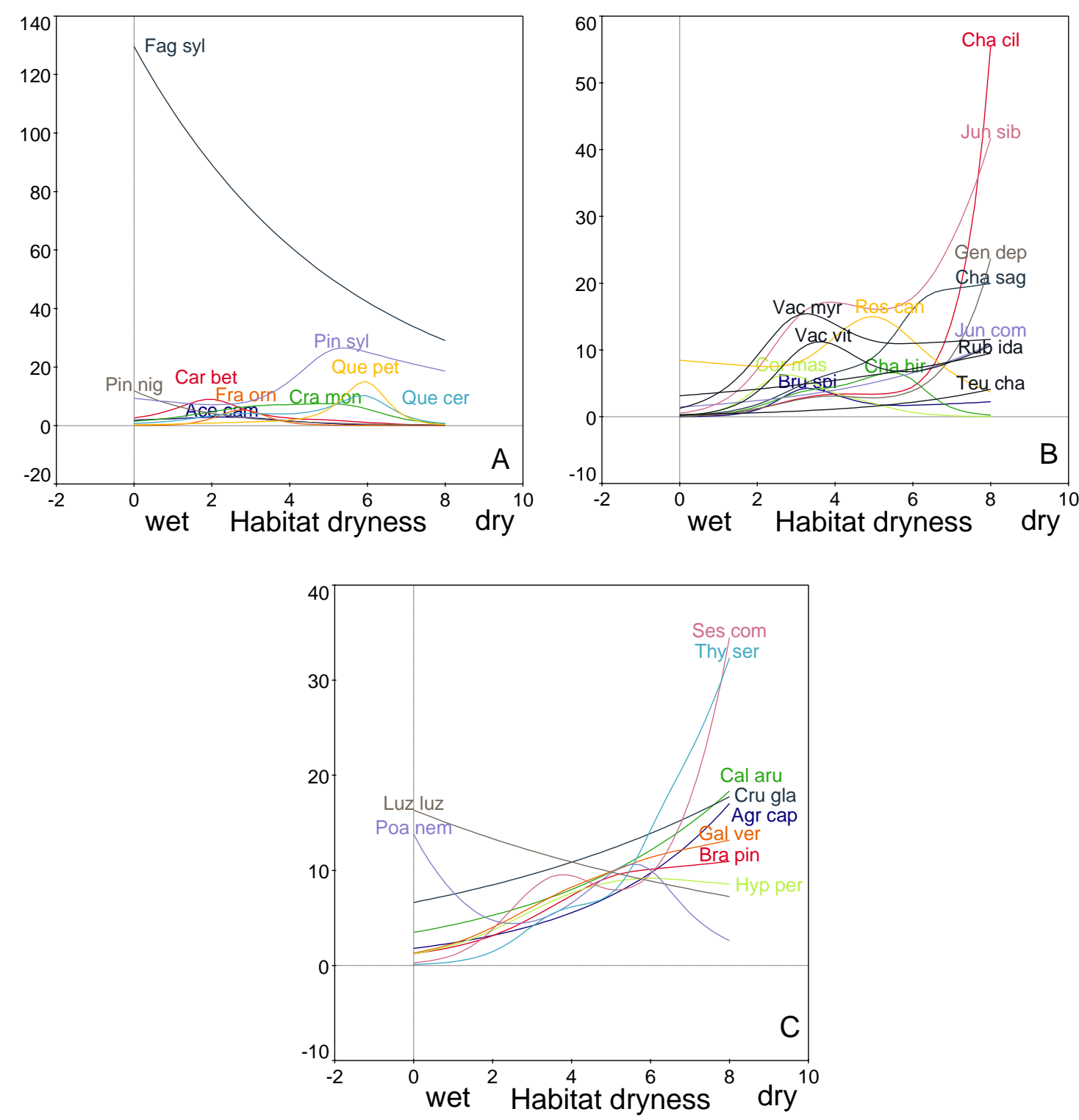

Figure 6. Response curves of dominant plant species along habitat dryness gradient. $a=$ Trees; $b=$ Shrubs; $c=$ Herbs. Species names are coded with the first three letters of the genus and species names (see Fig. 1). For species names not shown in Fig. 1, see Fig. 5.

\section{Species mode distribution}

Table 3 represents the statistical test for random (Poisson) species mode distribution. According to the first test, the herbs and all species taken together, have nonrandom mode distribution along the dryness and elevation gradients. The second test confirmed that they rather have clumped mode distribution. 
Table 3. Test summary for random and clumped distribution of species modes. The test is based on the mode frequency distribution in the context of habitat dryness and elevation. If modes are randomly distributed, then mode frequency should have Poisson distribution (i.e. Chi-squared test for Poisson distribution should not be statistically significant). If modes are clumped, then Kolmogorov-Smirnov test for Negative Binomial distribution should not be significant. Mass species are those 25 plant species among all species with the greatest mean importance value.

$$
n s=\text { not significant }
$$

\begin{tabular}{llccllll}
\hline Growth form & Chi-squared & $\boldsymbol{d} \boldsymbol{f}$ & $\boldsymbol{P}$ & Distribution & $\boldsymbol{D}$ & $\boldsymbol{P}$ & Distribution \\
\hline \multicolumn{7}{c}{ Elevation } \\
\hline Trees & 8.71 & 9 & $0.464(n s)$ & Random & - & - & - \\
Shrubs & 6.79 & 9 & $0.659(n s)$ & Random & - & - & - \\
Herbs & 20.39 & 9 & 0.016 & Nonrandom & 0.195 & $0.728(n s)$ & Clumped \\
\hline Mass species & 10.85 & 9 & 0.286 & Random & - & - & - \\
\hline All species & 23.49 & 9 & $<0.01$ & Nonrandom & 0.286 & $0.274(n s)$ & Clumped \\
\hline & & Dryness & & & & \\
\hline Trees & 7.90 & 5 & $0.162(n s)$ & Random & - & - & - \\
Shrubs & 7.72 & 5 & $0.172(n s)$ & Random & - & - & - \\
Herbs & 28.00 & 5 & $<0.001$ & Nonrandom & 0.224 & $0.807(n s)$ & Clumped \\
\hline Mass species & 8.78 & 5 & 0.118 & Random & - & - & - \\
\hline All species & 35.51 & 5 & $<0.001$ & Nonrandom & 0.322 & $0.382(n s)$ & Clumped \\
\hline
\end{tabular}

Table 4 represents the statistical test for lognormal and lograndom mode distribution.

Table 4. Kolmogorov-Smirnov goodness of fit test for lognormal and lograndom mode frequency distribution by growth forms and for all plant species. $n s=$ not significant .

\begin{tabular}{llll}
\hline Growth form & Expected distribution & $\boldsymbol{D}$ & $\boldsymbol{P}$ \\
\hline Trees & Lognormal & 0.498 & 0.013 \\
& Lograndom & 0.319 & $0.258(n s)$ \\
\hline Shrubs & Lognormal & 0.612 & $<0.001$ \\
& Lograndom & 0.386 & $0.101(n s)$ \\
\hline Herbs & Lognormal & 0.605 & $<0.001$ \\
& Lograndom & 0.664 & $<0.001$ \\
\hline All species & Lognormal & 0.300 & $0.325(n s)$ \\
& Lograndom & 0.554 & 0.004 \\
\hline
\end{tabular}

Species mode distribution, grouped by importance value octaves, is shown on Figure 7. 


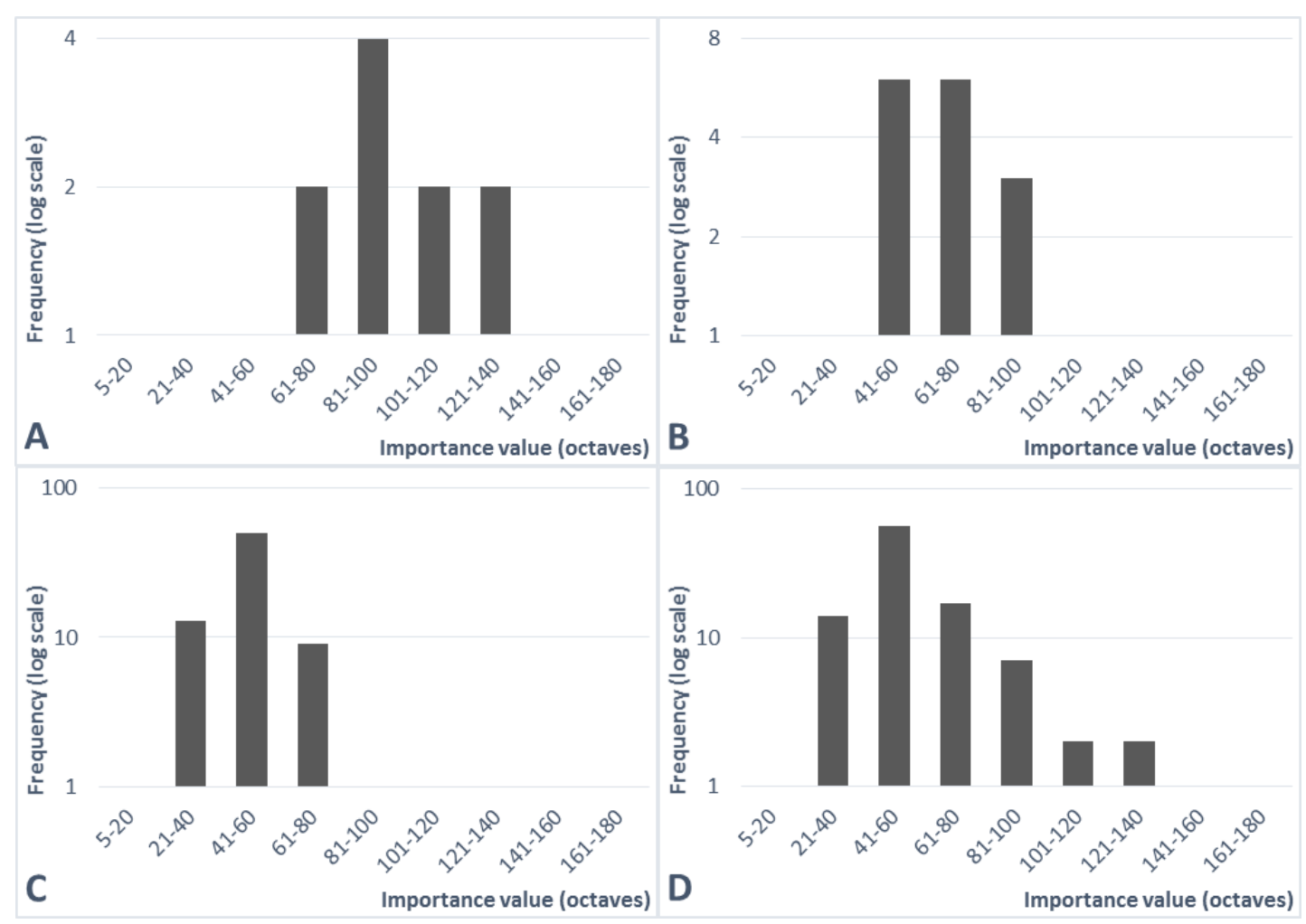

Figure 7. Histograms of importance value mode frequency distribution of all 100 dominant plant species and by growth forms. Note that the ordinate is logarithmic scale. $A=$ Trees; $B=$ Shrubs; $C=$ Herbs; $D=$ All species.

Analyzed separately, tree and shrub species had lograndom distribution but the modes of all species, taken together, had lognormal distribution. Unfortunately, we were not able to fit successively any of the suspected mode distributions to herb species alone - they had neither lograndom nor lognormal mode distribution.

\section{Discussion}

\section{Species response surface/curve shape}

The hypothesis that species response curve/surface along the environmental gradients takes symmetric (Gaussian) shape has been revised. The species response curves were plotted along the two main gradients separately. Based on our results (Table 2) we confirmed that almost all plant species have asymmetric or complex response surfaces/curves, which leads us to reject the Gauch and Whittaker (1972) hypothesis that species curves along environmental gradients are mainly symmetric (Gaussian).

Austin (1976) analyzed published by that time species response curves including the classical studies of R. H. Whittaker (Whittaker, 1956; Whittaker, 1960). He has found that asymmetrical and complex curves are much more frequent. According to another study (Austin, 1987), response curves of eucalypts that have been analyzed along the mean annual temperature gradient were mainly asymmetrical. Minchin (1989) also showed that the asymmetric and complex surfaces are rather more frequent than the symmetric ones, concluding that Gaussian model is too simple and even unacceptable. 
Similar results were reported in other contemporary studies (Austin, 1999; Austin, 2002; Austin, 2007).

Greig-Smith (1983) commented that there is not theoretical basis for the expectation of symmetric curves because the species physiological response to the environmental gradients is basically asymmetric. Therefore, there is not obvious reason that the relationship between plant species should lead to symmetric curves or surfaces (Austin, 1980). However, Palmer (1993) comments that, despite some exceptions, Gaussian model of mode distribution is applicable for most ecological studies. For him, Gaussian functions are attractive because they are controlled by small number of parameters, leading to elegant demonstrations of preliminary stated hypotheses and useful simplifications.

Minchin (1989) comments that the basic issue in studying species curves comes from the choice of variables expressing environmental gradients. Most environmental gradients are complex (Whittaker, 1967), i.e. they include variation of multiple variables but only few of them influence directly the plant species. Elevation, on its own, do not have direct effect on plants but we use it in our study, as well as numerous previous investigations, as an index of position (Minchin, 1989) along the complex gradient. Direct variables have their different aspects of air temperature, soil conditions, wind disturbances, snow cover endurance, etc. along the complex gradients. Moreover, the elevation can be measured comparatively easy and, most importantly, it has strong rank correlation with the direct gradients in a restricted geographic area (Minchin, 1989). Habitat dryness index, which we have used, is also complex gradient expressing the variability of soil moisture regime (moisture availability during the driest period, waterlogging period, etc.) and other soil variables like rock outcrops, humus layer depth etc. (Minchin, 1989).

Well known weakness in species curve and surface investigation is that often important environmental gradient are neglected or missed in the ecological studies. Complex surfaces can be result from uneven sample distribution along the important environmental gradients (Austin et al., 1984; Minchin, 1989). Another reason for obtaining complex surfaces instead of symmetric ones can be the different scale of observation or sampling strategy. For example, our study covers $118 \mathrm{~km}^{2}$ with fairly intensive sampling design (159 samples), compared to some previous studies covering much greater territories with relatively smaller sample number (Whittaker, 1956; Whittaker, 1960; Whittaker and Niering, 1965). Most previous studies analyzed the species curves along one or two complex gradients. Our choice of environmental gradients is based on a preliminary indirect gradient analysis where the greatest part of data variation was explained by few complex gradients. The different number of environmental gradients used simultaneously could also be the cause of complex and asymmetric curves and surfaces.

We showed that the plant species from different growth forms can have distinct responses towards the environmental gradients. We also found differences in the response surface shape between the growth forms. Minchin (1989) claims that the vegetation pattern can be visualized by summing distributional pattern of different growth forms. However, we prefer detailed division, for example, by plant functional types or growth forms, which allows more in-depth analyses.

Based on our results, for a future studies of species spatial distribution, we recommend the use of several environmental gradients instead of one or two. If possible, sampling designs should be intensive with, for example, at least 300 samples 
per $200 \mathrm{~km}^{2}$. Accumulated data is better to be analyzed with nonlinear techniques for species distribution modelling, like GAM or LOESS, which will guarantee adequate description of vegetation pattern.

\section{Species mode distribution}

We have tested several hypotheses concerning species mode distribution in the environmental space. The first one claimed that minor species modes are dispersed along the gradients randomly and the dominant species modes are uniformly distributed (Gauch and Whittaker, 1972). Our test of the tree, shrub and mass species mode distribution contradicts the tested hypothesis that minor species modes are distributed along the complex gradients randomly as well as the hypothesis of Gauch and Whittaker (1972) that dominant species are dispersed uniformly. So, the two hypothesis were rejected.

Another set of propositions stated that when species modes are grouped in octaves (classes) along environmental gradients the number of species in the classes is: 1) equal, implying lograndom distribution, 2) uneven, suggesting lognormal distribution, or 3) modes are clumped, having negative binomial distribution. We confirmed the lograndom distribution for tree and shrub species, but rejected the first two hypothesis for herbs - they had clumped distribution. Confirming the lograndom distribution of trees leads us to accept the Gauch and Whittaker (1972) proposition that tree species are equally distributed along the environmental gradients. Nevertheless, we confirmed the hypothesis that "large number of forest herbs and shrubs" have lognormal mode distribution (Table 4, last two rows).

The theory of ecological niche assumes that each species has its fundamental niche along any environmental gradient. In the presence of strong competitors, however, plant species become restricted to their realized niche (species ecological response toward the environment). Species realized niche may not match its fundamental one (its physiological response toward the environment) which is caused by the presence of stronger competitor (Mueller-Dombois and Ellenberg, 1974). This phenomenon was known and have been shown previously (Austin, 2005). In our case, herb species clumped distribution by no means can be attributed to species association, but contrary, it can result from the similar physiological requirements of the outcompeted plant species. The intricate interaction between plant physiological requirements and interspecific competition, which could be incorporated in the statistical modelling for better results (Austin, 2002), leads to the complex responses that we have obtained. Ellenberg and Strutt (2009) determine the species-specific physiological conditions and competition as primary organizing factors for the emergent vegetation pattern too.

Minchin (1989) claims that the hypotheses of Gauch and Whittaker (1972) for mode distribution are rather simplistic and can be very different in the various growth forms and not always in agreement with the lognormal or lograndom distribution. We have tested some of the hypotheses concerning vegetation pattern but to solidify a new theory for vegetation organization, understanding of the processes shaping the vegetation appearance is needed (Minchin, 1989). This could be achieved only by experiments (Shipley and Keddy, 1987). However, until a clearer picture of vegetation pattern has not emerged, there is a real risk of spending resources for experiments, leading to discoveries of non-existing vegetation phenomena (Minchin, 1989).

Analyzing the limiting ecological factors to plant species along the soil water table gradient, Shipley and Keddy (1987) tried to differentiate the continuum and community 
theories. Their results gave them reason to reject both theories. The dichotomy continuum-community should be abandoned and replaced by other working hypotheses trying to explain vegetation pattern (Shipley and Keddy, 1987).

According to Austin (2005), a series of hypotheses show that the differences between community and continuum concepts are rather insignificant and that their distinction would require detailed data and strict statistical methods. On the basis of our results, however, we conclude that species do not form associations (despite the herb species clumped distribution) which is obvious from the random tree and shrub distribution along gradients. On the contrary, it seems that each species has its own response shape towards the environment, determined by its physiology, interaction with other species (Pellissier et al., 2010) and historical events (White, 1979). Therefore, there is no two species with matching distribution along the environmental gradients.

\section{Conclusions}

In summary, we conclude that plant species rarely form symmetric surfaces/curves along environmental gradients but, rather, they are almost always asymmetric or complex. Mode distribution of dominant tree and shrub species is random but that of herbs follows clumped pattern. When species mode distribution is divided into octaves, trees and shrubs show lograndom distribution but all species together have lognormal one. Herbs, analyzed separately, do not conform to neither lognormal nor lograndom distributional patter. We hope that the current study will add a little drop to the vast ocean of vegetation ecology knowledge helping with the clarification of the basic understanding of the vegetation pattern, where after, with the help of experimental researches, it can be proceeded to deeper understanding of vegetation processes.

Acknowledgements. The author is thankful to Dragomir Zahariev and Eli Pavlova for their tireless help on the field. This study was partly funded by University of Forestry's (Sofia) Scientific Fund Grant No 47/1304, 2009.

\section{REFERENCES}

[1] Austin, M. P. (1976): On Non-Linear Species Response Models in Ordination. Vegetatio. 33: 33-41.

[2] Austin, M. P. (1980): Searching for a Model for Use in Vegetation Analysis. - Vegetatio. 42: 11-21.

[3] Austin, M. P. (1985): Continuum Concept, Ordination Methods, and Niche Theory. Annual Review of Ecology and Systematics. 16: 39-61.

[4] Austin, M. P. (1987): Models for the Analysis of Species' Response to Environmental Gradients. -Vegetatio. 69: 35-45.

[5] Austin, M. P. (1999): The Potential Contribution of Vegetation Ecology to Biodiversity Research. - Ecography. 22: 465-484.

[6] Austin, M. P. (2002): Spatial prediction of species distribution: an interface between ecological theory and statistical modelling. - Ecological Modelling. 157: 101-118.

[7] Austin, M. P. (2005): Vegetation and environment: discontinuities and continuities. - pp. 52-84 In: E. Van der Maarel (ed.). Vegetation ecology. Blackwell Publishing, City.

[8] Austin, M. P. (2007): Species distribution models and ecological theory: A critical assessment and some possible new approaches. - Ecological Modelling. 200: 1-19. 
[9] Austin, M. P., \& P. Heyligers (1990): New approach to vegetation survey design: gradsect sampling. pp. 31-36In: C. Margules, and M. Austin (eds.). - Nature Conservation: Cost Effective Biological Surveys and Data Analysis. CSIRO, City.

[10] Austin, M. P., \& T. M. Smith (1989): A New Model for the Continuum Concept. Vegetatio. 83: 35-47.

[11] Austin, M. P., R. B. Cunningham, \& P. M. Fleming (1984): New Approaches to Direct Gradient Analysis Using Environmental Scalars and Statistical Curve-Fitting Procedures. - Vegetatio. 55: 11-27.

[12] Carol, J., L. Benejam, C. Alcaraz, A. Vila-Gispert, L. Zamora, E. Navarro, J. Armengol, \& E. García-Berthou (2006): The effects of limnological features on fish assemblages of 14 Spanish reservoirs. - Ecology of Freshwater Fish. 15: 66-77.

[13] Clements, F. E. (1936): Nature and Structure of the Climax. - Journal of Ecology. 24: 252-284.

[14] Cleveland, W. S., \& S. J. Devlin (1988): Locally Weighted Regression: An Approach to Regression Analysis by Local Fitting. - Journal of the American Statistical Association. 83: 596-610.

[15] Curtis, J. T. (1959): The Vegetation of Wisconsin: An Ordination of Plant Communities. - University of Wisconsin Press.

[16] Dyakov, N. (2012): Classification of forest vegetation on the south slope of Vitosha Mountain, Western Bulgaria. - Forestry Ideas. 43: 57-77.

[17] Dyakov, N. (2013): Successional Pattern, Stand Structure and Regeneration of Forest Vegetation According to Local Environmental Gradients. - Ecologia Balkanica. 5: 69-85.

[18] Dyakov, N. (2014): Gradient analysis of vegetation on the south slope of Vitosha mountain, Southwest Bulgaria. - Applied Ecology and Environmental Research. 12: 1003-1025.

[19] Dyakov, N., \& P. Zhelev (2013): Alien species invasion and diversity of riparian forest according to environmental gradients and disturbance regime. - Applied Ecology and Environmental Research. 11: 249-272.

[20] Ellenberg, H. H., \& G. K. Strutt (2009): Vegetation Ecology of Central Europe. Cambridge University Press.

[21] Franklin, J. (1998): Predicting the distribution of shrub species in southern California from climate and terrain-derived variables. - Journal of Vegetation Science. 9: 733-748.

[22] Gauch, H. G., Jr., \& R. H. Whittaker (1972): Coenocline Simulation. - Ecology. 53: 446451.

[23] Gleason, H. A. (1926): The Individualistic Concept of the Plant Association. - Bulletin of the Torrey Botanical Club. 53: 7-26.

[24] Greig-Smith, P. (1983): Quantitative Plant Ecology. - University of California Press.

[25] Guisan, A., \& N. E. Zimmermann (2000): Predictive habitat distribution models in ecology. - Ecological Modelling. 135: 147-186.

[26] Guisan, A., \& W. Thuiller (2005): Predicting species distribution: offering more than simple habitat models. - Ecology Letters. 8: 993-1009.

[27] Guisan, A., S. Weiss, \& A. Weiss (1999): GLM versus CCA spatial modeling of plant species distribution. - Plant Ecology. 143: 107-122.

[28] Holm, S. (1979): A Simple Sequentially Rejective Multiple Test Procedure. Scandinavian Journal of Statistics. 6: 65-70.

[29] Jongman, R. H. G., C. J. F. ter Braak, \& O. F. R. van Tongeren (1995): Data Analysis in Community and Landscape Ecology. - Cambridge University Press.

[30] Krebs, C. J. (1999): Ecological Methodology. - Benjamin/Cummings.

[31] Minchin, P. R. (1989): Montane Vegetation of the Mt. Field Massif, Tasmania: A Test of Some Hypotheses about Properties of Community Patterns. - Vegetatio. 83: 97-110.

[32] Mueller-Dombois, D., \& H. Ellenberg (1974): Aims and Methods of Vegetation Ecology.- Wiley. 
[33] Palmer, M. W. (1993) Putting Things in Even Better Order: The Advantages of Canonical Correspondence Analysis. - Ecology. 74: 2215-2230.

[34] Peet, R. K., \& O. L. Loucks (1977): A Gradient Analysis of Southern Wisconsin Forests. - Ecology. 58: 485-499.

[35] Pellissier, L., K. Anne Bråthen, J. Pottier, C. F. Randin, P. Vittoz, A. Dubuis, N. G. Yoccoz, T. Alm, N. E. Zimmermann, \& A. Guisan (2010): Species distribution models reveal apparent competitive and facilitative effects of a dominant species on the distribution of tundra plants. - Ecography. 33: 1004-1014.

[36] Shipley, B., \& P. Keddy (1987): The individualistic and community-unit concepts as falsifiable hypotheses. pp. 47-55In: I. C. Prentice, and E. van der Maarel (eds.). - Theory and models in vegetation science. Springer Netherlands, City.

[37] Šmilauer, P. (1999-2003): CanoDraw for Windows, version 4.1. Glenn Randers-Pehrson.

[38] Spearman, C. (1904): The Proof and Measurement of Association between Two Things. The American Journal of Psychology. 15: 72-101.

[39] Systat Software, I. (2011): SigmaPlot for Windows, version 12.3.

[40] ter Braak, C. J. F. (1986): Canonical Correspondence Analysis: A New Eigenvector Technique for Multivariate Direct Gradient Analysis. - Ecology. 67: 1167-1179.

[41] ter Braak, C. J. F., \& I. C. Prentice (1988): A Theory of Gradient Analysis. pp. 271317In: A. H. F. E. D. F. M. Begon, and A. Macfadyen (eds.). - Advances in Ecological Research. Academic Press, City.

[42] ter Braak, C., \& P. Šmilauer (1997-2003) CANOCO for Windows, version 4.51. Biometrics, Plant Research International, Wageningen, The Netherlands.

[43] Thuiller, W., M. B. Araújo, \& S. Lavorel (2003): Generalized Models vs. Classification Tree Analysis: Predicting Spatial Distributions of Plant Species at Different Scales. Journal of Vegetation Science. 14: 669-680.

[44] van der Maarel, E., \& J. Franklin (2012): Vegetation Ecology. - Wiley.

[45] White, P. (1979): Pattern, process, and natural disturbance in vegetation. - Bot. Rev. 45: 229-299.

[46] Whittaker, R. H. (1956): Vegetation of the Great Smoky Mountains. - Ecological Monographs. 26: 2-80.

[47] Whittaker, R. H. (1960): Vegetation of the Siskiyou Mountains, Oregon and California. Ecological Monographs. 30: 279-338.

[48] Whittaker, R. H. (1967): GRADIENT ANALYSIS OF VEGETATION*. - Biological Reviews. 42: 207-264.

[49] Whittaker, R. H. (1978): Ordination of plant communities. - In: R. H. Whittaker (ed.) Handbook of vegetation science, City.

[50] Whittaker, R. H., \& W. A. Niering (1965): Vegetation of the Santa Catalina Mountains, Arizona: A Gradient Analysis of the South Slope. - Ecology. 46: 429-452.

[51] Yee, T. W., \& N. D. Mitchell (1991): Generalized Additive Models in Plant Ecology. Journal of Vegetation Science. 2: 587-602.

[52] Zar, J. H. (2010): Biostatistical Analysis. - Prentice Hall. 